RESEÑA

\title{
La misión Hasekura: 400 años de su legado en las relaciones entre México y Japón
}

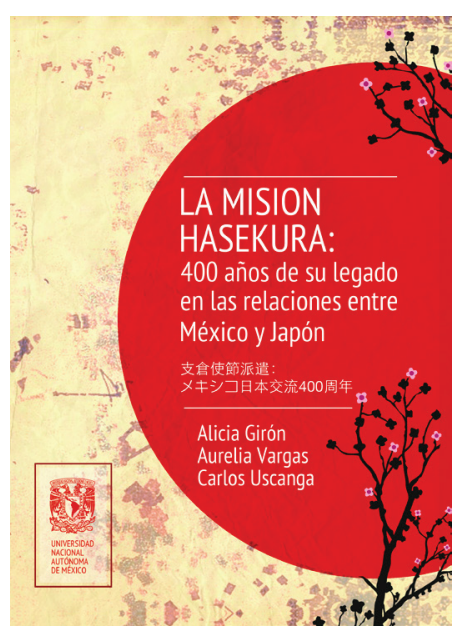

Filológicas y la Facultad de Ciencias Políticas y Sociales.

El sueA, ahora Programa Universitario de Estudios sobre Asia y África (PUEAA), fue la semilla por parte de la Universidad Nacional Autónoma de México (UNAM) para fortalecer la investigación y el trabajo académico sobre un continente que en los últimos años ha ganado relevancia, en gran medida debido a su desarrollo económico. Se trata del continente asiático, que, para muchos investigadores, será de gran importancia política, geoestratégica y cultural en las próximas décadas. En ese contexto nació este libro, en el que académicos e investigadores coincidieron en el papel relevante de Japón con México, sus relaciones comerciales desde hace décadas y lo que representa-

1. Universidad Nacional Autónoma de México, Facultad de Ciencias Políticas y Sociales. Mario de la Cueva s/n, Ciudad Universitaria, C.P. 04510 Ciudad de México, México. ORCID: http://orcid. org/0000-0003-1165-0909. Correo electrónico: dannyfresc@gmail.com 
ron en los niveles diplomático e histórico, cuando ambas naciones estaban creciendo como gobiernos independientes.

En el continente asiático, Japón se destacaba en asuntos económicos, además de estar geográficamente cerca de la gran China, del Imperio Mongol - que expandía sus conquistas territoriales-y del Imperio Coreano, también en expansión. Sin embargo, a pesar de ser un continente que no se ha estudiado a fondo, hasta hoy en día, se concluye que los principales países de Asia del Este: China, Corea y Japón, deben tener una mayor cooperación internacional con México.

De manera acertada, el libro se divide en cuatro secciones a) Japón como objeto de estudio ; b) Misión Hasekura: una revaloración histórica; c) El sistema económico regional y por último d) Lengua y Literatura.

Contar con la colaboración de especialistas, académicos e investigadores de la región Asia-Pacífico y Japón, hace de La Misión Hasekura: 400 años de su legado en las relaciones entre México y Japón, una referencia obligada para toda persona interesada en el país del Sol Naciente.

En la parte introductoria, el Excelentísimo Señor Embajador, Suichiro Megata, ofrece una pequeña explicación de los 400 años de amistad entre México y Japón, y habla sobre la misión que realizó el samurái Hasekura Tsunenaga, la cual inició en el año de 1613, con 140 japoneses, y cruzó el Océano Pacífico para llegar al puerto de Acapulco en el año 1614, en ese entonces la Nueva España, y que tenía como objetivo establecer relaciones comerciales de manera más directa.

En la primera sección, uno de los historiadores más destacados de la UNAM, Lothar Knauth, resalta la importancia de Japón como objeto de estudio en México, y explica cómo se inicia el interés por el país asiático en el campus universitario, hasta formar los centros de estudios que después, por razones organizativas, no pudieron concretarse y tuvieron que cerrar.

En la segunda sección, en la revaloración histórica, los especialistas escriben sobre el recién creado servicio diplomático de Japón, el vago concepto jurídico que se tenía en comparación con Europa y cómo los nipones tuvieron que abrirse al exterior para poder diversificar sus relaciones comerciales. La diplomacia japonesa también evolucionó a lo largo de los años, a pesar de que México no era independiente en ese entonces y estaba bajo el dominio del rey Felipe III, Japón se dispuso a establecer relaciones con la Corona española. Pero, ¿por qué se eligió a Hasekura como representante del país? Las autoridades japonesas se dieron cuenta de sus habilidades de negociación, de su 
desenvolvimiento en diferentes ambientes, y del conocimiento y la aplicación del protocolo de sus gobernantes, a quienes tenía una profunda lealtad.

Lo que se esperaba de la Misión Hasekura, cuando viajó a México, era obtener técnicas y herramientas para poder llevar el conocimiento a Japón, principalmente para el sector minero. Sin embargo, fue en el año 1888, con la firma del Tratado de Amistad, Comercio y Navegación, cuando oficialmente se establecieron las relaciones económicas y comerciales entre ambos países una vez que México fue independiente. Desde ese entonces los lazos de fraternidad no se han interrumpido.

En la tercera sección se habla sobre los intercambios comerciales entre ambos países; al comienzo, lo que más buscaba Japón era la plata de la Nueva España. Cuando el material era llevado al continente asiático, se podía intercambiar con China, y esta se abría comercio con Europa. Así que el metal fue verdaderamente apreciado para los japoneses, además de la tecnología y el conocimiento que tenían los mexicanos en el área de la minería, sobre todo la famosa técnica beneficio de patio, que consistía en separar la plata de otros minerales. Desde ese momento Japón comienza a trabajar, y hoy en día es una de las principales economías del mundo (De la Vega, 2015).

En la cuarta sección se abarcan distintos temas sobre lengua y literatura. La lengua es una parte fundamental para entender otra cultura, es la puerta para comprender cómo piensan las personas de determinado lugar. Debido a la importancia que estaba representando estudiar a Japón y formar especialistas en el país, no solo en temas políticos, económicos y de negocios, sino también personas que entendieran profundamente la cultura japonesa.

Todo idioma tiene sus dificultades; las recomendaciones que hacen los profesores que enseñan japonés — según las encuestas que muestra la última sección de este libro- son: tener constancia, por parte de los alumnos; realizar más dinámicas para la integración del grupo, y no solo conocer la lengua, sino también aspectos de la vida cotidiana, las tradiciones y costumbres en sí. No cabe duda del gusto que tienen los mexicanos o hispanohablantes por la lengua japonesa, lo que provoca el aumento de escuelas con el objetivo principal de enseñar al público interesado en el japonés.

Finalmente, los últimos capítulos nos hablan sobre la traducción de diversos escritos literarios del japonés al español y viceversa. También mencionan a Higuchi Ichiyō y las maravillosas aportaciones que hizo con sus escritos y estilo refinado, combinando lo antiguo con lo moderno, y las traducciones que han hecho varios autores japoneses de obras latinoamericanas. 
Sin duda alguna, el libro La misión Hasekura: 400 años de su legado en las relaciones entre México y Japón es una compilación de trabajos de grandes especialistas en la materia que nos describen de manera muy sencilla las relaciones México-Japón desde el comienzo, los obstáculos que enfrentó y cómo continúan hoy en día.

\section{Referencias}

De la Vega, V. S. (2015), "La plata de la Nueva España. Promotora de las relaciones comerciales entre América, Asia y Europa”, en A. Girón, A. Vargas \& C. Uscanga (coords.), La misión Hasekura: 400 años de su legado en las relaciones entre México y Japón, México, UNAM, pp. 75-87. 